\title{
Some DADNE Originated Cyclic Isomers - A DFT Study
}

\section{Lemi Türker}

Department of Chemistry, Middle East Technical University, Üniversiteler, Eskişehir Yolu No: 1, 06800 Çankaya/Ankara, Turkey; e-mail: lturker@gmail.com; lturker@metu.edu.tr

\begin{abstract}
Diaminodinitroethylene (DADNE) has three constitutional isomers, geminal, cis and trans. The geminal one is the well known FOX-7 explosive. It is a push-pull type molecule. In the present study, within the restrictions of density functional theory at the level of B3LYP/6-311++G(d,p), two cyclic dimeric structures of DADNE are investigated quantum chemically. Also their mono ionic forms have been investigated (unrestricted treatment). All the structures are found to be stable. Various quantum chemical and spectral data are collected computationally and discussed.
\end{abstract}

\section{Introduction}

Three structural isomers of diaminodinitroethylene are geminal, cis- and trans ones of which the geminal one has reputation as FOX-7 [1]. FOX-7, 1,1-diamino-2,2dinitroethylene, is also known as DADNE or DADE. Its synthesis was achieved in 1998 by members of the Swedish Defense Research Agency (FOI) [2, 3]. Its explosive potential was investigated thoroughly [4-18]. The nitration of 4,6-dihydroxy-2methylpyrimidine and then its hydrolysis is the other method of synthesis of FOX-7 [19].

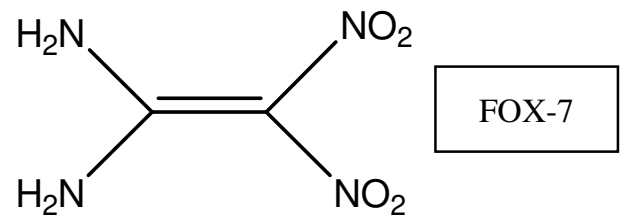

Received: June 6, 2020; Accepted: July 10, 2020

Keywords and phrases: DADNE, FOX-7, push-pull, explosive, density functional.

Copyright (C) 2020 Lemi Türker. This is an open access article distributed under the Creative Commons Attribution License, which permits unrestricted use, distribution, and reproduction in any medium, provided the original work is properly cited. 
FOX-7 is a novel high-energy insensitive energetic material (IM) having low sensitivity beside its good thermal stability. It possesses excellent application performance among the insensitive ammunitions and solid propellants. Although no structural resemblance exists between FOX-7 and RDX or HMX they are expressed by the same $\mathrm{C} / \mathrm{H} / \mathrm{N} / \mathrm{O}$ ratio however FOX-7 is much less sensitive than RDX (in terms of impact, friction, and electrostatic discharge sensitivities [20]).

Although its very simple molecular composition and structure, FOX-7 has surprisingly abundant chemical reactivity, due to the twos of the amino and nitro groups present in its structure [21, 22]).

Of the many polymorphic forms FOX-7 has, it is known that the $\alpha$-form reversibly turns into $\beta$-form by heat treatment [23, 24]. It has been observed that at higher temperature, $\beta$-polymorph undergoes an irreversible conversion to $\gamma$-phase which undergoes decomposition at $504 \mathrm{~K}$ [23]. Its decomposition has been extensively investigated computationally [25]. Also the effect of high pressure on the crystal structure of FOX-7 has been searched [26].

FOX-7 is an attractive ingredient for application in high performance insensitive munition (IM) compliant explosive recipes. It has been reported that FOX-7 also possesses the ability of increasing the burning rate in propellants. Because of that it attracts attention for high performance propellants [1].

Many of a FOX-7 based propellant formulations have been studied in order to obtain a composite propellant with inherent IM-properties but reduced or minimum smoke producing character [27].

On the other hand, some thermo chemical calculations have indicated that PBX's based on FOX-7 and energetic binders could serve as a replacement of Comp-B even at rather low solid loadings. A plastic bound explosive based on FOX-7 and an energetic binder have been prepared [28].

The effects of nitration and epoxidation on the ballistic properties of FOX-7 were also investigated within the realm of density functional theory (DFT) [29]. Various ground state properties of FOX-7 were calculated based on B3LYP/aug-cc-pVDZ predictions [30].

To achieve safer features for insensitive munitions (IM) or explosive devices, laser ignitibility of FOX-7 was investigated in order to achieve the direct optical ignition of insensitive explosives [31]. 
Recently, some novel derivatives of FOX-7 (geminal DADNE) and their properties as energetic materials have been reported [32, 33]. In the present study, some cyclic isomers, originated from DADNE have been investigated within the constraints of density functional theory (DFT).

\section{Method of Calculation}

In the present study, the initial structural optimizations of all the structures leading to energy minima have been achieved by using MM2 method followed by semi-empirical PM3 self-consistent fields molecular orbital (SCF MO) method [34, 35] at the restricted level [36, 37]. Subsequent optimizations were achieved at Hartree-Fock level using various basis sets. Then, the structural optimizations were managed within the framework of density functional theory (DFT) [38, 39] at the level of B3LYP/6$311++G(d, p)$ [37, 40]. The exchange term of B3LYP consists of hybrid Hartree-Fock and local spin density (LSD) exchange functions with Becke's gradient correlation to LSD exchange [39, 41]. The correlation term of B3LYP consists of the Vosko, Wilk, Nusair (VWN3) local correlation functional [42] and Lee, Yang, Parr (LYP) correlation correction functional [43]. Also, the vibrational analyses have been done. The total electronic energies are corrected for the zero point vibrational energy (ZPE). The normal mode analysis for each structure yielded no imaginary frequencies for the $3 \mathrm{~N}-6$ vibrational degrees of freedom, where $N$ is the number of atoms in the system. This indicates that the structure of each molecule corresponds to at least a local minimum on the potential energy surface. For the mono ionic forms of the structures which are open shell systems, the optimizations have been done at the level of UB3LYP/6-311++G(d,p). All these calculations were done by using the Spartan 06 package program [44].

\section{Results and Discussion}

In the present study, two condensed dimeric structures originating from geminal DADNE (FOX-7) and cis DADNE are considered for a computational treatment. Those structures are theoretically generated by the elimination of one molecule of hydrogen from two molecules of the parent compounds (intermolecular union). Structures-I and II from the conjugation point of view of are isoconjugate with some even alternant hydrocarbon anions $[45,46]$. The isoconjugate models of I and II (see Figure 1) are nonKekulé and Kekulé [45, 46] structures, respectively having certain numbers of starred 
$\left(\mathrm{n}^{*}\right)$ and unstarred $\left(\mathrm{n}^{0}\right)$ positions. A non-Kekulé structure is characterized with $\Delta \mathrm{n} \geq 2$ where $\Delta n=n^{*}-n^{0}[45,47]$. It is known that most of the explosive molecules like FOX-7 (geminal DADNE) are isoconjugate with non-Kekulé alternant hydrocarbons (or their anions). Note that FOX-7 has $n^{*}=7$ (note the coincidence of 7 in the name of FOX-7) and $n^{\circ}=4$. Whereas the isoconjugates of structures I and II have $n^{*}=12$ and $n^{\circ}=6$. Thus, structures-I and II are characterized with $\Delta \mathrm{n}=6$ (See Figure 1).
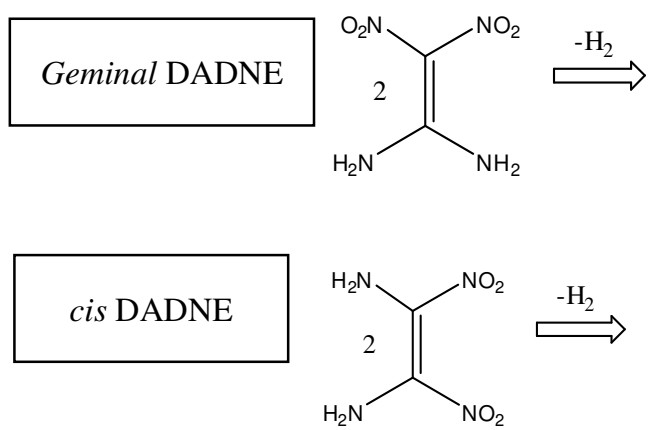

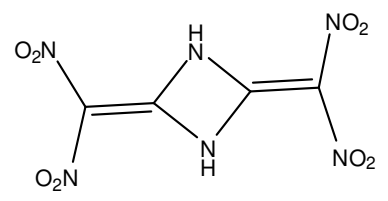<smiles>O=[N+]([O-])C1=C([N+](=O)[O-])NC([N+](=O)[O-])=C([N+](=O)[O-])N1</smiles>

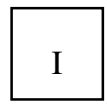

II

Note that the criterion of having an isoconjugate non-Kekule alternant hydrocarbon is a necessary but not a sufficient condition for explosive molecules [48].

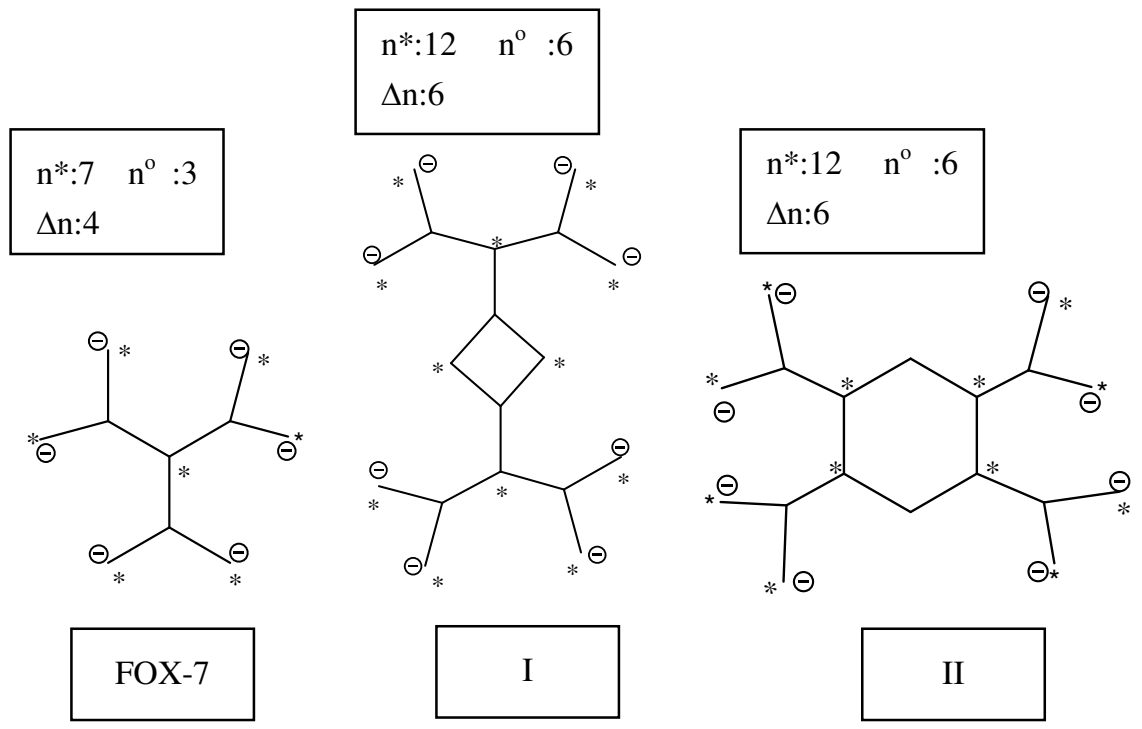

Figure 1. The $\sigma$-skeletons of isoconjugate models for FOX-7 and structures I and II. 
Figure 2 shows the optimized structures of I and II in two different angles of view. The figure also displays the direction of the dipole moment vectors. Note that in structure-II the vector is perpendicular to the surface of the hexagonal ring (piperazine ring). The magnitudes of the vectors, together with some other properties, are shown in Table 1 . They have $\mathrm{C} 1$ symmetry, therefore in spite of the highly symmetrical formulas of them the dipole moments have some nonzero values.
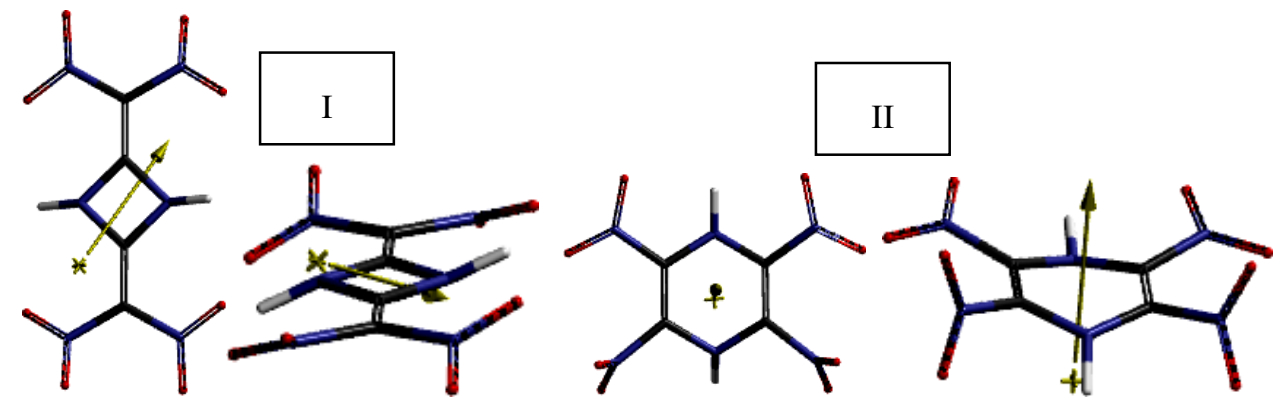

Figure 2. Optimized structures of I and II in two different angles of view.

Oxygen balance (OB) is an important factor for explosive molecules which indicates whether it has enough oxygen or not to achieve internal redox during the explosion [20]. Otherwise, some oxidizing agents are added into the explosive composition. FOX-7 has OB value of -21.62 whereas the isomeric structures considered presently have OB: -6.1 .

Table 1. Some calculated properties of the structures I and II.

\begin{tabular}{lccccccc}
\hline & $\begin{array}{c}\text { Dipole } \\
\text { moment } \\
(\text { Debye })\end{array}$ & $\begin{array}{c}\text { Pt } \\
\text { group }\end{array}$ & $\begin{array}{c}\text { Area } \\
\left(\AA^{2}\right)\end{array}$ & $\begin{array}{c}\text { Volume } \\
\left(\AA^{3}\right)\end{array}$ & Ovality & $\log \mathbf{P}$ & Polarizability \\
\hline I & 0.01 & $\mathrm{C} 1$ & 218.31 & 180.37 & 1.41 & 1.72 & 55.06 \\
II & 1.96 & $\mathrm{C} 1$ & 215.61 & 178.59 & 1.41 & 1.72 & 55.20 \\
\hline
\end{tabular}

Figure 3 displays the ESP charges on the atoms of structures I and II. Note that the ESP charges are obtained by the program based on a numerical method that generates charges that reproduce the electrostatic potential field from the entire wavefunction [44]. 


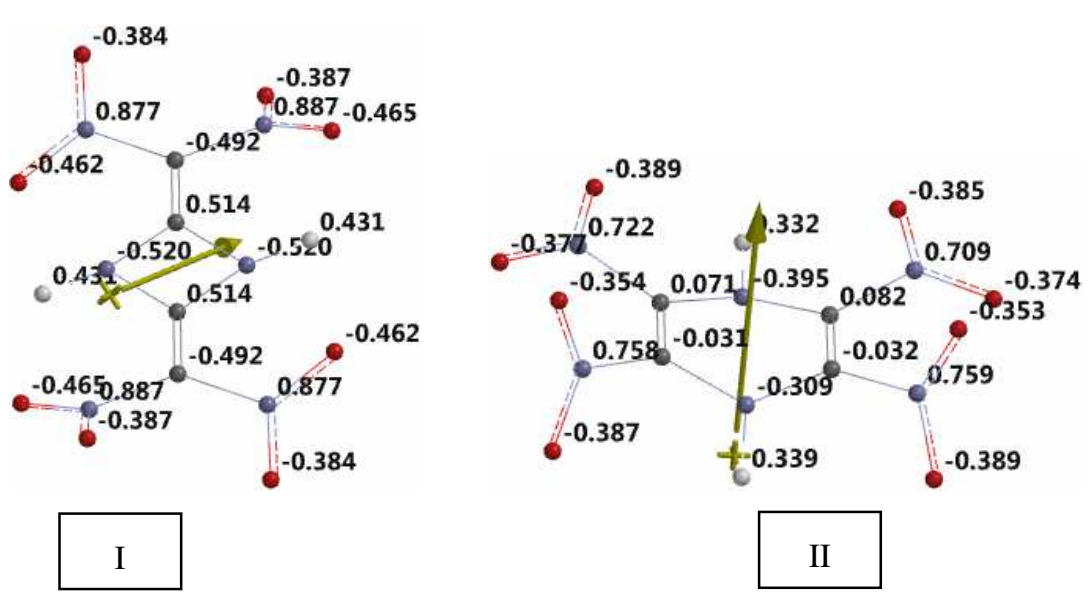

Figure 3. The ESP charges on atoms of the structures considered.

Table 2 shows some energies of the structure-I and II where E, ZPE and $E_{C}$ are the total electronic energy, zero point vibrational energy and the corrected total electronic energy, respectively. The data in the table indicate that both of the structures are electronically stable but I is more stable than II. Rationalization of this result can be achieved by the resonance theory, because in structure-I lone-pair of NH groups can be delocalized over the nitro groups in parallel fashion to each other or independently from each other. Whereas in structure-II, the nitro groups at the lower (or upper) part of the structure (Figure 3) are in cross conjugation with NH groups nearby. In other words, in structure-I facilitated delocalization is operative and it has a smaller dipole moment.

Table 2. Some energies of the structures considered.

\begin{tabular}{cccc}
\hline Structure & $\mathbf{E}$ & $\mathbf{Z P E}$ & $\mathbf{E}_{\mathbf{C}}$ \\
\hline I & -2845410.71 & 280.05 & -2845130.66 \\
II & -2845405.27 & 280.40 & -2845124.87 \\
\hline
\end{tabular}

Energies in $\mathrm{kJ} / \mathrm{mol}$.

Figure 4 shows the calculated IR spectra of structures I and II. Although, they are isomers of each other and have the same types of bonding their IR spectra are somewhat different. In structure-I, the peak at $3616 \mathrm{~cm}^{-1}$ corresponds to N-H stretching, whereas the one at $1666 \mathrm{~cm}^{-1}$ stands for carbon-carbon stretching coupled with skeletal breathing 

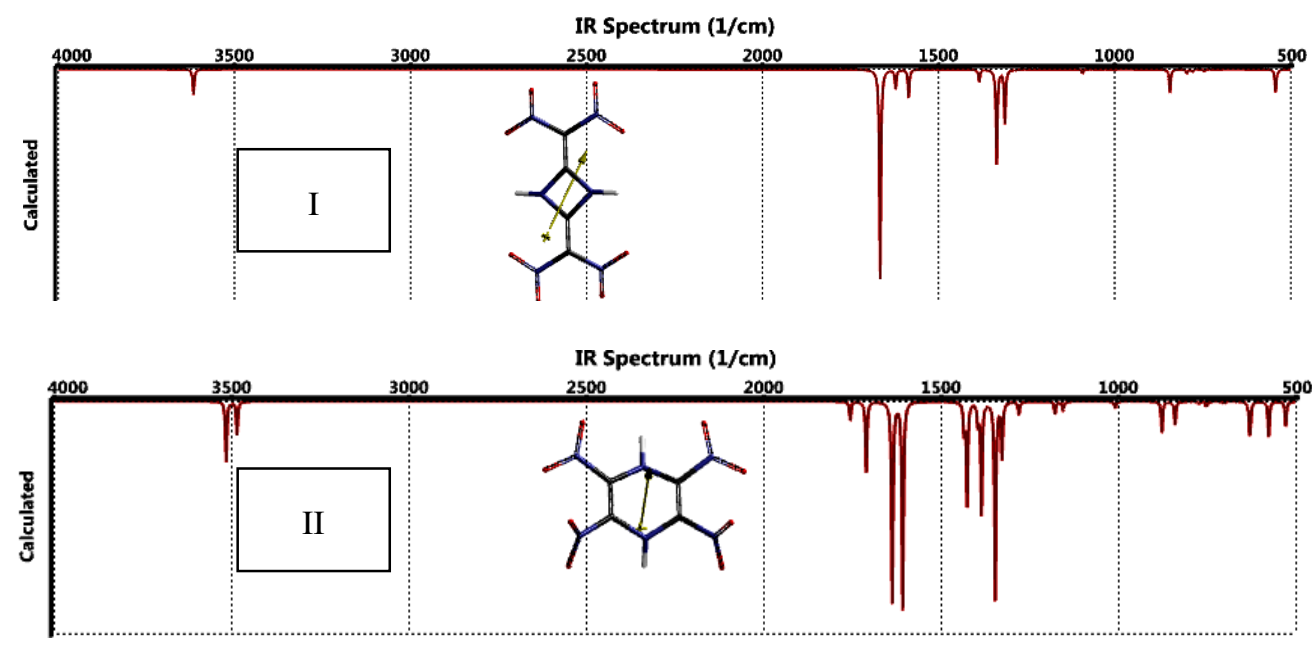

Figure 4. Calculated IR spectra of the structures I and II.

of the ring. The other huge peak at $1335 \mathrm{~cm}^{-1}$ is for various bending vibrations. In the spectrum of II the peaks at $3515 \mathrm{~cm}^{-1}$ and $3485 \mathrm{~cm}^{-1}$ are N-H stretchings. The carboncarbon stretchings occur at $1711 \mathrm{~cm}^{-1}$ coupled with asymmetrical C-NH stretchings and $\mathrm{C}-\mathrm{NO}_{2}$ bending vibrations. The bendings of N-H moieties occur at $1427 \mathrm{~cm}^{-1}$ and 1387 $\mathrm{cm}^{-1}$. In the region of $1387 \mathrm{~cm}^{-1}-1329 \mathrm{~cm}^{-1}$ the $\mathrm{NO}_{2}$ vibrations occur.

Figure 5 displays some of the molecular orbital energy distribution of structures I and II. Table 3 contains the HOMO, LUMO energies $\left(\varepsilon_{\mathrm{HOMO}}\right.$ and $\left.\varepsilon_{\mathrm{LUMO}}\right)$ and the interfrontier energy gaps $\left(\varepsilon_{\mathrm{LUMO}}-\varepsilon_{\mathrm{HOMO}}\right)$ of these isomeric structures. Structure-I has lower HOMO and LUMO energies than the respective energies of II but the LUMO energies are more comparable than the HOMO energies. Note that electron attracting groups in alternant systems lower both the HOMO and LUMO energy levels at unequal extents. It is due to magnitude of where the heteroatom perturbation has occurred on the isoconjugate system. Thus, the molecular orbital coefficient magnitudes are to be considered. 


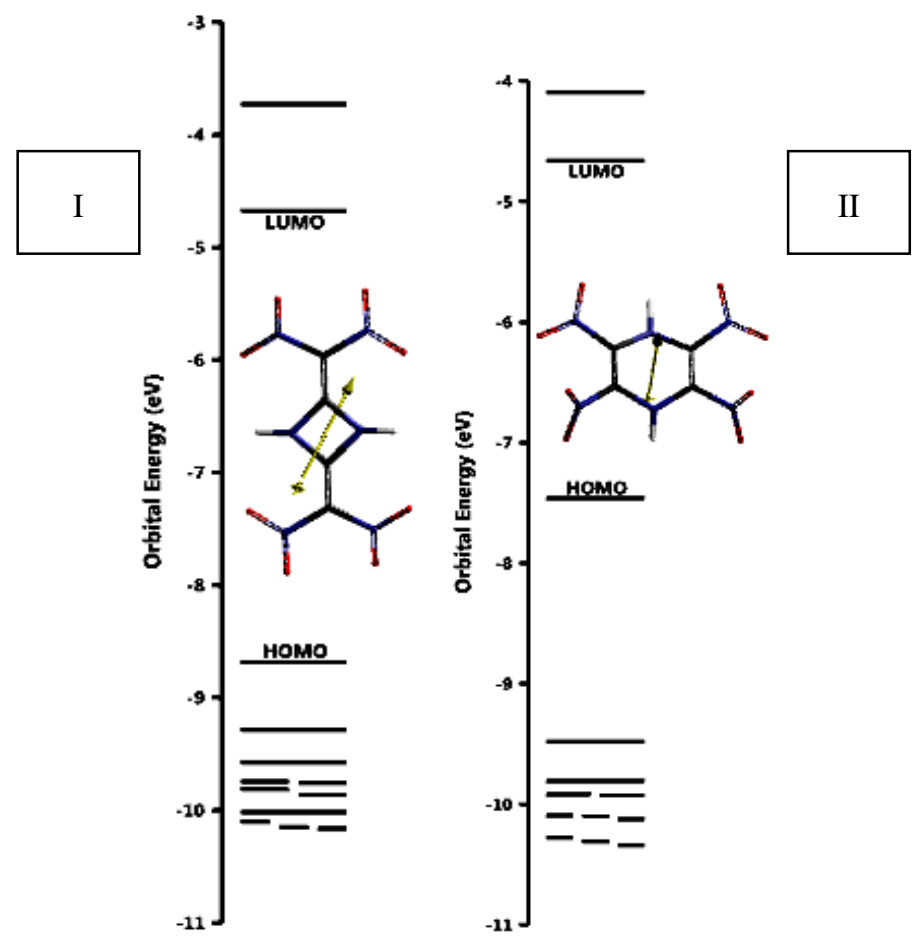

Figure 5. Some of the molecular orbital energy levels of the structures.

On the other hand, electron donating substituents raise up both of the frontier molecular orbitals at unequal extents and are dictated again by the magnitudes of the heteroatom perturbations, thus the magnitudes of the molecular orbital coefficients of the isoconjugate alternating hydrocarbon systems. The interfrontier molecular orbital energy gap of structure-I is greater than the respective value of II.

Table 3. The HOMO, LUMO energies and $\Delta \varepsilon$ values of the structures.

\begin{tabular}{cccc}
\hline & HOMO & LUMO & $\Delta \boldsymbol{\varepsilon}$ \\
\hline I & -837.97 & -451.02 & 386.95 \\
II & -719.97 & -449.41 & 270.56 \\
\hline
\end{tabular}

Energies in $\mathrm{kJ} / \mathrm{mol}$.

Figure 6 stands for the HOMO and LUMO patterns of structures I and II. As seen in the figure the frontier molecular orbitals of structure-I exhibits some sorts of $\pi$ symmetry. It is also true in a great extent for the LUMO of structure-II. 

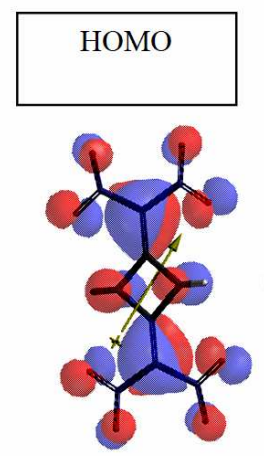

\section{LUMO}
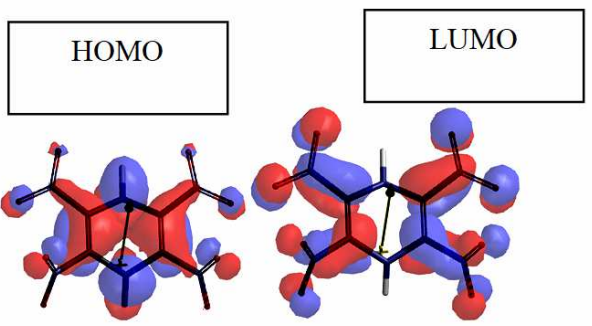

Figure 6. The HOMO and LUMO patterns of the structures I and II.

Figure 7 shows the time-dependent UV-VIS spectra of the structures considered. Since, the frontier molecular orbital energy gap of structure-II is narrower than the respective value of structure-I, the spectrum of II exhibits a good deal of bathochromic shift to visible part of the spectrum. It is known that an extended conjugation narrows the frontier molecular orbital energy gap [49], thus causes a bathochromic shift. Hence, in structure-II there should be a better extended conjugation compared to structure-I. Moreover, in structure-II more than one $\lambda_{\max }$ values exist implying the existence of many chromophoric excitations.
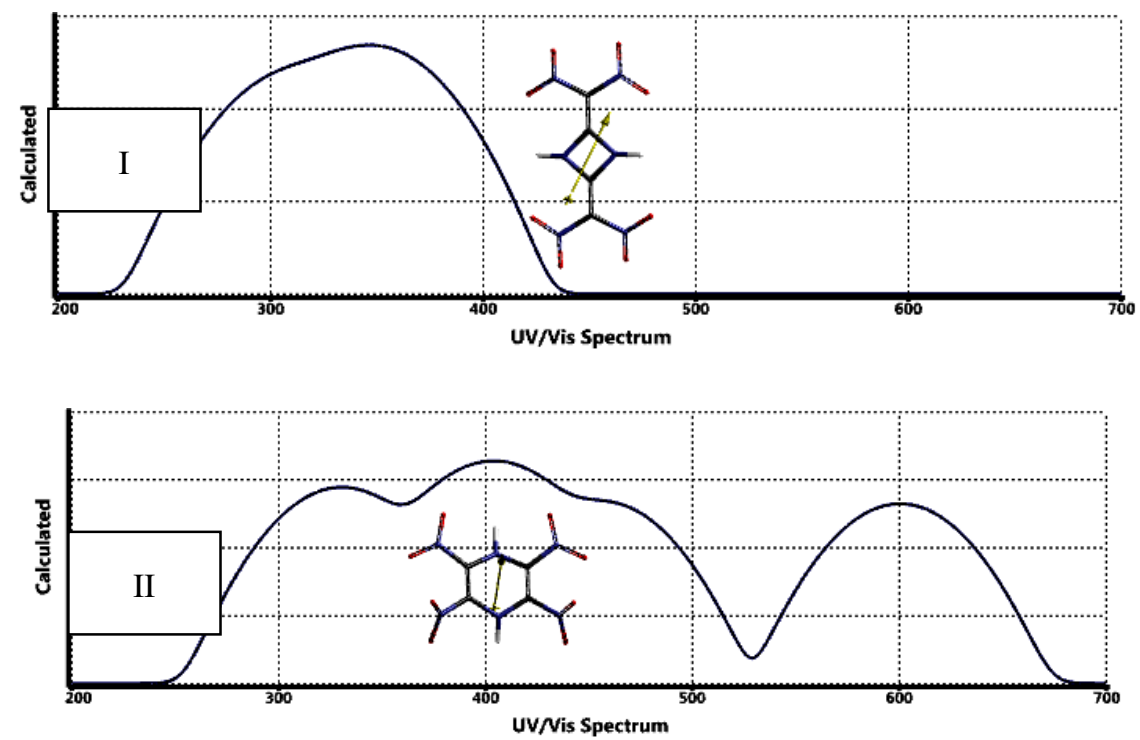

Figure 7. Calculated UV-VIS spectra of the structures. 
The impact sensitivity is associated and rationalized with magnitudes of $\Delta \varepsilon$ values. Since structure-II has much narrower frontier molecular orbital (FMO) energy gap, then it should be more susceptible to impact stimulus, because as the FMO energy gap $(\Delta \varepsilon)$ becomes less and less the impact sensitivity increases more and more [50, 51].

\section{Charged Forms}

Safety has prime importance in handling and storage of explosive materials. Quite often electric static charges accumulate on those materials and might initiate violent explosions. Hence, an investigation on the charged forms of novel structures I and II may shed some light on the electrostatic stability of them. Presently, mono ionic forms of the structures are considered. The anionic forms of I and II are labeled as IA and IIA, respectively. In a similar fashion the cations have labels as IC and IIC, respectively. Figure 8 shows the optimized structures of the mono ionic forms of structures I and II. Note that those ionic forms are open shell systems. Therefore, in this part the calculations are performed at the unrestricted level (UB3LYP/6-311++G(d,p)). The figure reveals that structural stability exists while the structures turn into the corresponding mono ionic species.
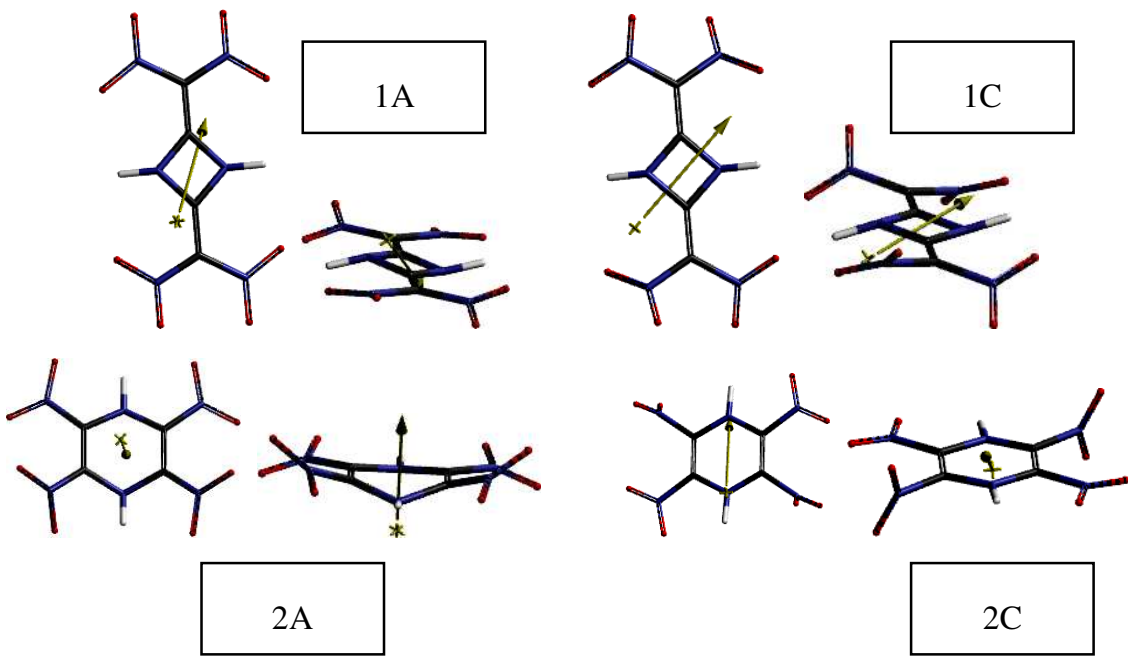

Figure 8. Optimized structures of the mono ions considered (From two different angles of view).

Table 4 shows some energies of the charged forms considered. The data reveal that anion and cation of structure-II is more stable than anion and cation of structure-I. In other words, structure-II stabilizes the negative or positive charge better than structure-I. 
Table 4. Some energies of the charged forms.

\begin{tabular}{cccc}
\hline Structure & $\mathbf{E}$ & $\mathbf{Z P E}$ & $\mathbf{E}_{\mathbf{C}}$ \\
\hline 1A & -2845736.49 & 273.62 & -2845462.87 \\
2A & -2845764.71 & 274.30 & -2845490.41 \\
1C & -2844436.36 & 272.45 & -2844163.91 \\
2C & -2844575.76 & 277.92 & -2844297.84 \\
\hline
\end{tabular}

Energies in $\mathrm{kJ} / \mathrm{mol}$.

Table 5 shows the HOMO, LUMO energies and the interfrontier molecular orbital energy gaps $(\Delta \varepsilon)$ of the charged forms of structures I and II. The gap $(\Delta \varepsilon)$ is especially important because the impact sensitivity is associated and rationalized with $\Delta \varepsilon$ values. That is narrower the gap, more sensitive to impact the explosive is [50,51]. In that sense, the order of $2 \mathrm{~A}>1 \mathrm{~A}>2 \mathrm{C}>1 \mathrm{C}$ should be the impact sensitivity order of the present charged forms.

Table 5. The HOMO, LUMO energies and interfrontier molecular orbital energy gaps $(\Delta \varepsilon)$ of the charged forms.

\begin{tabular}{cccc}
\hline Structure & HOMO & LUMO & $\Delta \boldsymbol{\varepsilon}$ \\
\hline 1A & -200.91 & 5.42 & 206.33 \\
2A & -242.28 & -88.32 & 153.96 \\
1C & -1283.03 & -853.31 & 429.72 \\
2C & -1188.26 & -888.45 & 299.81 \\
\hline
\end{tabular}

Energies in $\mathrm{kJ} / \mathrm{mol}$.

Figure 9 shows some of the molecular orbital energy levels of the charged forms. Since the unrestricted calculations have been performed $\alpha$ - and $\beta$-orbitals arise (in the figure they are represented as a- and b-, respectively). 

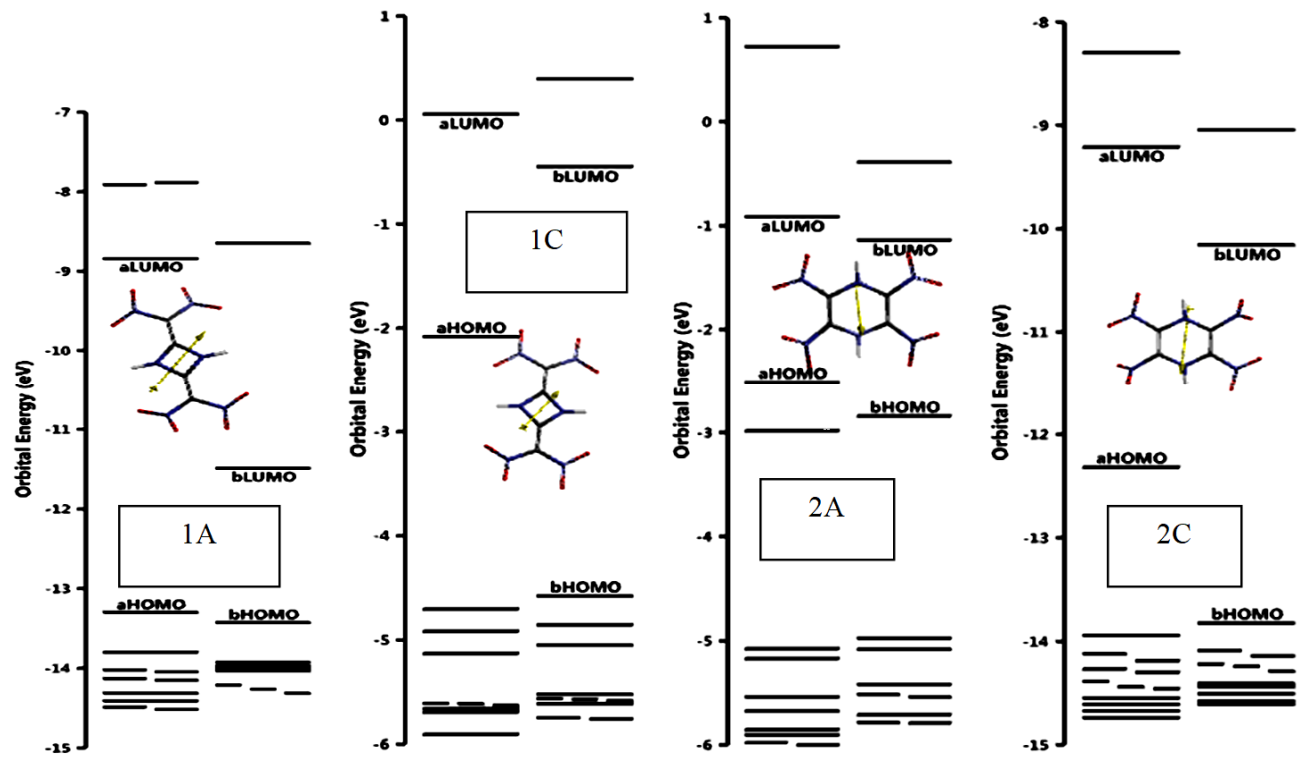

Figure 9. Some of the molecular orbital energy levels of the mono ions considered.

\section{Conclusion}

The present density functional treatment has revealed that the novel structures originated from geminal and cis DADNE are electronically stable. However structure-I is more stable than II although it has a four, whereas II has a six-membered ring systems. The UV-Vis spectra of II exhibits an appreciable bathochromic shift as compared to structure-I. Both of the structures have much better oxygen balance value than geminal DADNE (FOX-7).

Mono ionic forms of structures I and II have also been considered to get some idea about their electrostatic stability. Both of them preserved their structural integrity in the mono ionic state. Structure-II between the neutral ones and its mono anionic form among the charged forms are expected to be more sensitive to impact than the others within the same class.

\section{References}

[1] J. P. Agrawal, High Energy Materials, Weinheim: Wiley-VCH, 2010. https://doi.org/10.1002/9783527628803 
[2] P. Politzer and J. S. Murray, Energetic Materials, Part 1, Amsterdam: Elsevier, 2003.

[3] I. J. Lochert, FOX-7 - A New Insensitive Explosive, DSTO Aeronautical and Maritime Research Laboratory, 506 Lorimer St, Fishermans Bend, Victoria 3207 Australia, AR012-065, November 2001.

[4] N. V. Latypov, J. Bergman, A. Langlet, U. Wellmar and U. Bemm, Synthesis and reactions of 1,1-diamino-2,2-dinitroethylene, Tetrahedron 54 (1998), 11525-11536. https://doi.org/10.1016/S0040-4020(98)00673-5

[5] U. Bemm and H. Östmark, 1,1-Diamino-2,2-dinitroethylene: A novel energetic material with infinite layers in two dimensions, Acta Crystallogr. C 54 (1998), 1997-1999. https://doi.org/10.1107/S0108270198007987

[6] N. V. Latypov, A. Langlet and U. Wellmar, New chemical compound suitable for use as an explosive, intermediate and method for preparing the compound, Patent WO99/03818, 1999.

[7] H. Östmark, H. Bergman, U. Bemm, P. Goede, E. Holmgren, M. Johansson, A. Langlet, N. V. Latypov, A. Petterson, M. L. Petterson, N. Wingborg, C. Vörde, H. Stenmark, L. Karlsson and M. Hihkiö, 2,2-dinitro-ethene-1,1-diamine (FOX-7)-Properties, analysis and scale-up, $32^{\text {nd }}$ International Annual Conference of ICT on Energetic Materials - Ignition, Combustion and Detonation, Karlsruhe, Germany, 2001.

[8] H. Östmark, A. Langlet, H. Bergman, N. Wingborg, U. Wellmar and U. Bemm, FOX-7 A new explosive with low sensitivity and high performance, The $11^{\text {th }}$ International Detonation Symposium, Colorado, USA, 1998.

[9] H. Bergman, H. Ostmark, A. Pettersson, M. L. Petterson, U. Bemm and M. Hihkio, Some initial properties and thermal stability of FOX-7, Insensitive Munitions and Energetic Materials Symposium (NDIA), Tampa, Florida, USA, 1999.

[10] W. A. Trzciński and A. Belaada, 1,1-Diamino-2,2-dinitroethene (DADNE, FOX-7) Properties and formulations (a review), Cent. Eur. J. Energ. Mater. 13(2) (2016), $527-$ 544. https://doi.org/10.22211/cejem/65000

[11] B. Janzon, H. Bergman, C. Eldsater, C. Lamnevik and H. Ostmark, FOX-7 - A high performance, low vulnerability high explosive for warhead applications, $20^{\text {th }}$ Int. Symp. Ballistics, Orlando, Florida, USA, September 23-27, 2002.

[12] Y. N. Matyushin, G. T. Afanas'ev, V. P. Lebedev, M. N. Mahov and V. I. Pepekin, TATB and FOX-7: Thermochemistry, performance, detonability, sensitivity, $34^{\text {th }}$ Int. Annu. Conf. ICT, Karlsruhe, Germany, June 24-27, 2003. 
[13] A. J. Bellamy, N. V. Latypov and P. Goede, Studies on the nitration of new potential precursors for FOX-7, New Trends Res. Energ. Mater., Proc. Semin., $7^{\text {th }}$, Pardubice, Czech Republic, April 20-22, 2004.

[14] S. Cudziło, Z. Chyłek and R. Diduszko, Crystallization and characterization of 1,1diamino-2,2-dinitroethene (DADNE), $36^{\text {th }}$ Int. Annu. Conf. ICT, Karlsruhe, Germany, June 28-July 1, 2005.

[15] W.A. Trzciński, S. Cudziło, Z. Chyłek and L. Szymańczyk, Investigation of sensitivity and detonation properties of FOX-7, $37^{\text {th }}$ Int. Annu. Conf. ICT, Karlsruhe, Germany, June 27-30, 2006.

[16] M. Anniyappan, M. B. Talawar, G. M. Gore, S. Venugopalan and B. R. Ganghe, Synthesis characterization and thermolysis of 1,1-diamino-2,2-dinitroethylene (FOX-7) and its salts, J. Hazard. Mater. B 137 (2006), 812-819.

https://doi.org/10.1016/j.jhazmat.2006.03.034

[17] W. A. Trzciński, S. Cudziło, Z. Chyłek and L. Szymańczyk, Detonation properties of 1,1diamino-2,2-dinitroethene (DADNE), J. Hazard. Mater. 157 (2008), 605-612. https://doi.org/10.1016/j.jhazmat.2008.01.026

[18] V. S. Mishra, S. R. Vadali, R. K. Garg, V. S. Joshi, R. D. Wasnik and S. Asthana, Studies on FOX-7 based melt cast high explosive formulations, Cent. Eur. J. Energ. Mater. (CEJEM) 10(4) (2013), 569-580.

[19] N. V. Latypov, M. Johansson, E. Holmgren, E. V. Sizova, V. V. Sizov and A. J. Bellamy, On the synthesis of 1,1-diamino-2,2-dinitroethene (FOX-7) by nitration of 4,6-dihydroxy-2-methylpyrimidine, Org. Process Res. Dev. 11(1) (2007), 56-59. https://doi.org/10.1021/op068010t

[20] T. M. Klapötke, Chemistry of High-Energy Materials, Berlin: De Gruyter, 2011. https://doi.org/10.1515/9783110227840

[21] Y. Zhang, Q. Sun, K. Xu, J. Song and F. Zhao, Review on the reactivity of 1,1- diamino2,2-dinitroethylene (FOX-7), Propellants Explos. Pyrotech. 41 (2016), 35-52. https://doi.org/10.1002/prep.201500065

[22] K. Baum, N.V. Nguyen, R. Gilardi, J. L. Flippen-Anderson and C. George, Nitration of 1,1-diamino-2,2-dinitroethylenes, J. Org. Chem. 57 (1992), 3026-3030.

https://doi.org/10.1021/jo00037a015

[23] J. Evers, T. M. Klapötke, F. Mayer, G. Oehlinger, J. Welch, $\alpha$ - and $\gamma$-FOX-7 polymorphs of a high energy density material, studied by X-ray single crystal and powder investigations in the temperature range from 200 to $423 \mathrm{~K}$, Inorg. Chem. 45 (2006), 4996-5007. https://doi.org/10.1021/ic052150m 
[24] M. J. Crawford, J. Evers, M. Göbel, T. M. Klapötke, P. Mayer, G. Oehlinger and J. M. Welch, $\gamma$-FOX-7: Structure of a high energy density material immediately, prior to decomposition, Propellants Explos. Pyrotech. 32 (2007), 478-495. https://doi.org/10.1002/prep.200700240

[25] A. Gindulytè, L. Massa, L. Huang and J. Karle, Proposed mechanism of 1,1-diaminodinitroethylene decomposition: a density functional theory study, J. Phys. Chem. 103 (1999), 11045-11051. https://doi.org/10.1021/jp991794a

[26] Z. A. Dreger, A. I. Stash, Z. G. Yu, Y. S. Chen, Y. Tao and Y. M. Gupta, High-pressure crystal structures of an insensitive energetic crystal: 1,1-diamino-2,2-dinitroethene, $J$. Phys. Chem. C 120 (2) (2016), 1218-1224. https://doi.org/10.1021/acs.jpcc.5b10644

[27] H. Lips and K. Menke, FOX-7/GAP rocket propellants for a shoulder launched projectile, $27^{\text {th }}$ International Symposium on Ballistics, Freiburg, Germany, April 22-26, 2013.

[28] S. Karlsson, H. Östmark, C. Eldsäter, T. Carlsson, H. Bergman, S. Wallin and A. Pettersson, Detonation and sensitivity properties of FOX-7 and formulations containing FOX-7, FOI, Swedish Defence Research Agency, Grindsjöns Research Center, SE-147 25, Tumba, Sweden, 2002.

[29] L. Türker and S. Varış, Effects of epoxidation and nitration on ballistic properties of FOX-7, Z. Anorg. Allg. Chem. (ZAAC) 639 (2013), 982-987.

https://doi.org/10.1002/zaac.201300086

[30] H. Dorsett, Computational Studies of FOX-7, A New Insensitive Explosive, DSTO Aeronautical and Maritime Research Laboratory, PO Box 1500, Salisbury, South Australia, AR-011-596, September, 2000.

[31] X. Fang and W. G. McLuckie, Laser ignitibility of insensitive secondary explosive 1,1diamino-2,2-dinitroethene (FOX-7), J. Hazard. Mater. 285(21) (2015), 375-82. https://doi.org/10.1016/j.jhazmat.2014.12.006

[32] T. Zhou, Y. Li, K. Xu, J. Song and F. Zhao, The new role of 1,1-diamino-2,2dinitroethylene (FOX-7): two unexpected reactions, New J. Chem. (2017), 1. https://doi.org/10.1039/C6NJ03370A

[33] H. Gao and J. M. Shreeve, Recent progress in taming FOX-7 (1,1-diamino-2,2dinitroethene), RSCAdv. (2016), 1. https://doi.org/10.1039/C6RA12412G

[34] J. J. P Stewart, Optimization of parameters for semiempirical methods I. Method, J. Comput. Chem. 10 (1989), 209-220. https://doi.org/10.1002/jcc.540100208 
[35] J. J. P Stewart, Optimization of parameters for semi empirical methods II. Application, $J$. Comput. Chem. 10 (1989), 221-264. https://doi.org/10.1002/jcc.540100209

[36] A. R. Leach, Molecular Modeling, Essex: Longman, 1997.

[37] P. Fletcher, Practical Methods of Optimization, New York: Wiley, 1990.

[38] W. Kohn and L. Sham, Self-consistent equations including exchange and correlation effects, J. Phys. Rev. 140 (1965), 1133-1138. https://doi.org/10.1103/PhysRev.140.A1133

[39] R. G. Parr and W. Yang, Density Functional Theory of Atoms and Molecules, London: Oxford University Press, 1989.

[40] C. J. Cramer, Essentials of Computational Chemistry, Chichester, West Sussex: Wiley, 2004.

[41] A. D. Becke, Density-functional exchange-energy approximation with correct asymptotic behavior, Phys. Rev. A 38 (1988), 3098-3100. https://doi.org/10.1103/PhysRevA.38.3098

[42] S. H. Vosko, L. Wilk and M. Nusair, Accurate spin-dependent electron liquid correlation energies for local spin density calculations: a critical analysis, Can. J. Phys. 58 (1980), 1200-1211. https://doi.org/10.1139/p80-159

[43] C. Lee, W. Yang and R. G. Parr, Development of the Colle-Salvetti correlation-energy formula into a functional of the electron density, Phys. Rev. B 37 (1988), 785-789. https://doi.org/10.1103/PhysRevB.37.785

[44] SPARTAN 06, Wavefunction Inc., Irvine CA, USA, 2006.

[45] M. J. S. Dewar, The Molecular Orbital Theory of Organic Chemistry, New York: McGraw-Hill, 1969.

[46] M. J. S. Dewar and R. C. Dougherty, The PMO Theory of Organic Chemistry, New York: Plenum-Rosetta, 1975. https://doi.org/10.1007/978-1-4613-4404-9

[47] I. S. Dmitriev, Molecules Without Chemical Bonds, Moscow: Mir Pub., 1981.

[48] L. Türker, Recent developments in the theory of explosive materials (371-404), in: Jansen JT (Ed.), Explosive Materials, New York: NOVA, 2011.

[49] I. Fleming, Frontier Orbitals and Organic Chemical Reactions, NY: Wiley, 1976.

[50] V. Anbu, K. A. Vijayalakshmi, R. Karunathan, A. David Stephen and P. V. Nidhin, Explosives properties of high energetic trinitrophenyl nitramide molecules: A DFT and AIM analysis, Arabian Journal of Chemistry 12(5) (2019), 621-632.

https://doi.org/10.1016/j.arabjc.2016.09.023 
[51] N. R. Badders, C. Wei, A. A. Aldeeb, W. J. Rogers and M. S. Mannan, Predicting the impact sensitivities of polynitro compounds using quantum chemical descriptors, Journal of Energetic Materials 24 (2006), 17-33. https://doi.org/10.1080/07370650500374326 